\title{
Gender Differences in the Use of FTAs when Reporting Incidents of UI: An Indian Study
}

\author{
Asha Kaul \\ ashakaul@iimahd.ernet.in \\ Phone: +91 7926324902 \\ Esha Patnaik \\ esha@iimahd.ernet.in
}

W.P. No. 2006-03-04

March 2006

The main objective of the working paper series of the IIMA is to help faculty members,

Research Staff and Doctoral Students to speedily share their research findings with professional colleagues, and to test out their research findings at the pre-publication stage

INDIAN INSTITUTE OF MANAGEMENT

AHMEDABAD-380 015

INDIA 


\title{
Gender Differences in the Use of FTAs when Reporting Incidents of UI: An Indian Study
}

\begin{abstract}
The study, conducted in an Indian organization, aims to examine differences, if any, across genders in the use of face threatening acts (FTAs) while reporting incidents of upward influence (UI). The nature of incidents reported for use of UI entails the possible use of FTAs, that is, challenging the positive or negative face of the target to achieve certain desired objectives. Given research evidence on the differences in communication styles between men and women, we examined the possibility of any such differences in the use of FTA in reported speech within an organization.

No significant differences were found between women and men in the use of FTAs. When the target was of the opposite gender as the agent, the latter was more likely to use either bald on-record or on-record with redressive action strategy for influencing. In cases where both the interactants were of the same gender, the agent generally used FTAs such as on-record with redressive action and solidarity politeness to gain compliance. A combination of UI strategies was employed in such instances.
\end{abstract}

Keywords: Gender, face threatening acts, upward influence, communication, face. 


\section{Gender Differences in the Use of FTAs when Reporting Incidents of UI: An Indian Study}

\section{Introduction}

Gender studies in organizations have gained significance in recent times, with more women entering the workforce. As they move up the hierarchical ladder, the scope for vertical communication across gender sees a simultaneous rise. Research studies have given varying results regarding the similarities and dissimilarities between the vertical communication patterns of the two groups. In this paper we study gender differences in oral communication using a moderating variable, namely Face Threatening Act (FTA), to study reported incidents of upward influence (UI) in organizations.

Influence, in the organizational context, is the process by which a member of the organization attempts to control the thinking, actions, or decision-making process of superiors, peers or subordinates. Thus, it is the intended or unintended effect of the agent (influencer) on the target's (to be influenced) attitude, perception or behavior (Yukl, 1998). Influence can be of two types vertical and horizontal. Vertical influence is used across the hierarchical structure of the organization. This again is of two types - downward and upward. While downward influence is that exercised by the superior over subordinates, through upward influence (UI) the employee tries to exert control over the thinking or decision making of superiors in the organization. Horizontal influence is exercised with peers, internal and external customers and other stakeholders in the organization. We have taken up UI as the focus of our present study.

Studies on the communication patterns of women and men indicate an observed difference between the two groups in their interaction patterns in general, and specifically in UI. However, this difference may be affected by various situational factors like role relationship, environment and individual differences, rather than gender differences (Mills, 2002).

Extending this last mentioned proposition, we analyzed Face Threatening Acts (FTAs) across genders to identify if FTAs were a product of gender differences or situational factors. Brown and Levinson (1987) proposed the theory of FTA which is based on the principle of 'face', that is the public self-image that every individual wants to claim for the self. This has two aspects - positive and negative face.

Studies on men and women in diverse organizational settings have demonstrated stereotypical behavior in interpersonal (Falbo and Peplau, 1980) and group situations (Eagley and Johnson, 1990; Mainiero, 1986). However, the role of context in the real or perceived difference in interactional behavior of men and women is yet to be extensively studied, particularly in the Indian scenario.

Study of FTA in the light of UI offers interesting possibilities. Three factors govern the use of FTA in an interaction between the agent and the target - the relative power distance between the agent and the target, the social distance between the two and the degree of imposition or urgency involved in the act of FTA (Brown and Levinson, 1987, p 15). The power differential and purposive interaction that underlie any attempt at UI pose potential threats to the face of an individual by challenging the assumptions of maintaining face in an interaction.

The objective of this study is to examine possible differences in the use of FTA between men and women while reporting incidents of UI in an organizational context. The paper discusses FTAs as a moderating variable. The role of FTA in successful (or unsuccessful) UI and possible gender differences in its use form the crux of the review presented here and the subsequent analysis and discussion. 
Practical difficulties arose in collecting data through direct observation or taping (video or audio) of incidents of UI in real situations. Interviewing people who have engaged in such interactions met this requirement. We did qualitative analysis of the data to study likely differences across gender in the application of FTA when employees engage in UI. The broader objective of studying communication patterns made a qualitative research approach suitable for capturing the nuances of the analysis.

\section{Review of literature}

With growing number of women joining the corporate sector, communications research is increasingly taking interest in the similarities and differences between the communication patterns of female and male managers (O'Neil, 2004; Wilkins and Andersen, 1991). Though the number of women managers is still small, they are gradually moving into higher managerial positions. This phenomenon increases the scope for vertical communication across gender and gives rise to several interesting research questions.

Against this background, research on UI gains importance because of the interplay of real and perceived differences across gender, power distance and the likely difference in criticality of the influence goal for the agent and the target. The successful (or otherwise) employment of influence strategies may result in a range of outcomes, from gaining a favourable result to even expulsion. Thus, the employee has to be careful in deciding whether or not to apply face threatening acts (FTAs) in an act of UI and how to use it effectively. In this paper we develop a framework to examine any likely differences across gender in the use of FTAs while reporting instances of UI.

\section{Gender}

Literature on gender studies has extensively compared the managerial styles of women and men in the workplace. The focus has been more on the differences in styles, rather than similarities. These differences have been attributed various reasons such as the work culture (Gersick, Bartunek and Dutton, 2000), self stereotyping (van Vianen and Fischer, 2002; Lamude, 1993), and work attributes. For example, men are generally found to employ direct and assertive influence strategies, while women tend to prefer agreement and pro-social emotional behavior (Johnson, 1976). These differences have been demonstrated both in mixed-sex and in same-sex groups (Johnson, Funk and Clay-Warner, 1995).

\section{Upward influence (UI)}

UI is the attempt to secure a desired response from someone higher in the formal hierarchy of an organization (Deluga and Perry, 1991; Kipnis and Schmidt, 1988; Liden and Mitchell, 1988). The effective use of UI strategies secures desired results for the subordinate and can be indicative of their level of success within the organization (Thacker and Wayne, 1995; Yukl and Tracey, 1992; Kipnis and Schmidt, 1988).

Kipnis and Schmidt's (1982) Profiles of Organizational Influence Scale (POIS) identifies six main categories of influence strategies - rationality/reason, ingratiation, exchange, assertiveness, coalition and upward appeal. These strategies may be described as follows (Falbe and Yukl, 1992): Reason is a direct strategy, based on logic and rationality. The use of reasoning for UI is directly proportionate to the goals and the needs of the agent (Waldera, 1988). Ingratiation is an informal tactic (Schilit and Locke, 1982) based on interpersonal attraction, impression management, and flattery (Kipnis and Vanderveer, 1971; Kipnis, Schmidt, and Wilkinson, 1980; Mechanic, 1962). At times employees might even ingratiate themselves with their superiors without intentionally meaning to (Gardner III, 1992). This could take the form of doing something for them or perhaps carrying out some activity not directly a part of the job profile.

The agent makes use of the exchange tactic by exchanging favours or bargaining for compliance by the target (Waldron, Hunt and D'Silva, 1993). Assertiveness is a pressure strategy (Falbe and Yukl, 1992) used when the employees are sure of their expertise and position. This is a direct or 'hard' tactic. Coalition refers to influence exerted in a group. The numerical strength of the group 
builds up majority opinion for the cause. When the subordinate convinces the superior by assuring agreement of higher authorities, it is referred to as upward appeal (Schilit and Locke, 1982). This may not be used as a primary tactic, but is resorted to when other tactics fail (Maslyn, Farmer and Fedor, 1996; Waldron, Hunt and D'Silva, 1993).

\section{Face threatening act (FTA)}

Individuals use language, behavior and gestures to present a certain self image to the world (Morand and Ocker, 2003). This self image, presented to others, is called face (Adams and Shepherd, 1996). Face may be of two types - negative, which is the desire to be distinct with freedom for unimpeded individual action, and positive, that is, the need to be assimilated, treated as equal and a desire for approval (Mills, 2002; Adam and Shepherd, 1996). Face wants arise out of an expectation that people with whom the individuals interact will affirm and maintain their face (Morand and Ocker, 2003).

There are two types of sub-faces for each of these - personal face or a desire concerning one's social standing, circumstances and relationship; and social face, that is, a desire concerning one's personality, property and preferences (Mills, 2002). Face threatening acts (FTAs) threaten either the agent's or the target's desire to be accepted (positive face) or their autonomy (negative face) (Knapp, Stafford and Daly, 1986). Positive face may be threatened through negative evaluations such as criticisms, accusations and contradictions, while negative face may be threatened through impeding actions such as orders, advice, requests and expression of anger or even admiration (Knapp, Stafford and Daly, 1986). Negative emotions are generated by a face threat and responses can range from embarrassment and mild irritation to open hostility (White, Tynan, Galinsky, and Thompson, 2004).

To reduce the degree of threat to face, interactants may use various politeness strategies (White, 1997) that may be elaborated as: bald on record, solidarity politeness, deference politeness, offrecord, or not say anything at all.

The bald-on-record approach is used when the interactants know each other well and there is minimum threat to face. There is not much effort to reduce the impact of the FTA ("Examples from Brown," n.d.; Ferencik, n.d.). The individual may go on-record with redressive action. While the directness of the threat to face is not reduced, the language used is toned down to reduce the impact (Morand and Ocker, 2003). Solidarity politeness is based on common ground. It minimizes threat through an expression of friendliness and bridging any gap between the interactants.

In deference politeness there is a serious imposition on the target's face so the agent tries to mitigate it through means such as indirectness, minimizing imposition and asking for forgiveness. Off-record uses indirectness and ambiguity to minimize imposition. The agent maintains ambiguity in the request, thus leaving it open for the target to take the hint and do something or choose to ignore it without direct confrontation. When the degree of threat to face is very high the agent may not say anything at all.

\section{Gender and UI}

Like stated earlier, more women are entering the managerial ranks, making gender studies important for understanding organizational dynamics and shaping of the work environment. The patterns of functioning of women and men, their similarities and differences govern interpersonal dynamics and ultimate achievement of organizational goals.

Research results have varied regarding gender differences in the use of UI strategies. While some have clearly brought out differences in their use, others see no clear-cut variation in how women and men employ these strategies. Some studies state that women use more indirect means (DuBrin, 1991) as compared with men when trying to influence their superior. In comparison men tend to employ the direct and hard tactics of reason (Baxter, 1984) and assertiveness (Johnson, 1976). Some researchers found women more effective in UI (Lauterbach and Weiner, 1996) while 
others found no difference between the two (Carli, 1989; Sagrestano, 1992; Kipnis, Schmidt and Wilkinson, 1980; Yukl and Tracey, 1992). A relevant question here is that whether differences, if any, are due to inherent differences between men and women or are socially and contextually governed.

\section{Gender, FTA and UI}

Existing research on UI has been largely conducted from the psychological, sociological and human resource perspective. While UI has been one of the relevant areas in organizational communication research, the medium of use of influence strategies, that is, language, has been mostly a neglected area (Kaul and Brammer, 2004).

FTAs lend themselves to regrettable messages (Knapp, Stafford and Daly, 1986). The use of FTAs can result in hostile behavior (White et al., 2004). An agent's use of FTA will be minimum or done away with if the threat to the target's face is high. Use of ambiguous language or indirectness (Riley, 1993) tempers or avoids the use of FTA by creating scope for alternative interpretations. Referring to the context in which FTA may be used, Adams and Shepherd (1996) held that the perceived threat to face will be lower when the context in which it is used is a legitimate one.

Examining how interactional and conversational aspects function in organizations, researchers have found social distance, relative power and the degree of imposition inherent in the request govern the use of FTAs (Morand and Ocker, 2003; White, 1997; Riley, 1993). The nature of UI inherently involves a request for compliance that poses a threat to face of the target. There is the possibility of rebuff, rejection, even formal action being taken against the subordinate. Some UI strategies will have a greater possibility of posing threat to face than others. Also, the degree to which the individual will risk threat to face will depend on the importance of the influence goal (Johnson, Roloff, and Riffee, 2004).

Ideally the employee will use tactics that will enable continuing in an organizationally acceptable manner. Given the relational and personal support that exists in a superior-subordinate relationship the interdependence is valued even more by both parties and any threat to face in such a scenario assumes greater significance (Adams and Shepherd, 1996).

Women and men have been attributed with different communication strategies. While the male stereotype is direct, aggressive, logical and impersonal, the female stereotype, in comparison, is soft-spoken, compliant and emotional (Baker, 1991). According to Jaffe, Lee, Huang and Oshagan (1995) men have been known to use more aggressive and 'problem-solving' oriented language while women employ more agreement, support and understanding in their interactions. Some research on gender and language show women to be more sensitive to politeness and issues of status than men (Guodong and Jing, 2005). The tendency of women to apologize more often (Jaffe at el., 1995) also supports this finding. However, there the differential effects due to the sex of the agent and the target in same sex and cross sex dyads have to be examined (Brown and Levinson, 1987, p30) more extensively to provide any conclusive evidence regarding interaction patterns in such dyads. Besides, gender and language cannot be assumed to have a direct one-toone correspondence (Gardner-Chloros and Finnis, n.d.). Gender being a socially and culturally shaped construct, the role of other social and environmental factors will affect the use of language across gender. The type of talk, rather than the gender per se (Gardner-Chloros and Finnis, n.d.) will govern the use of various communication strategies.

FTA can be operational in any act of interaction or communication. Disagreeing, asking a favor, requesting for information or goods, can all amount to a threat to face (Morand and Ocker, 2003). Positive tactics are based on an assumption of commonality of background of the agent and the target. Negative tactics are limited to the situation itself. Positive tactics are based on inclusion of both parties in an in-group. In negative tactics the agent may employ indirectness to gain compliance. The former can actually pose greater threat to face since they are based on the presupposition by the agent that there are certain commonalities between the two parties, an 
assumption that may not be shared by the target. Negative face recognizes the use of an imposition and attempts to moderate it through the use of indirectness and other linguistic means. The organizational and work culture, power distance in the organization and nature of interaction will play significant roles in the choice of tactic used to maintain face.

Against this background, we wanted to test if there is any difference across the gender of the agent in the use of FTA in reported speech of application of UI. We adopted the method of reported speech for the collection of primary data. Given the sensitiveness of such interaction, recording and/or the presence of an observer would have affected the authenticity of the process. The respondents' narration of the interaction of UI was based on their interpretation of how the interaction progressed, rather than objective documentation of the conversation. The purpose was to capture the intention, the overall process of interaction and the result of the interaction. Parts of the dialogues from the transcripts were qualitatively analyzed to study the likelihood of threat to face in the interactions.

\section{Methodology}

We conducted the study in the western zonal office of an Indian bank which has a ratio of 60:40 of men and women employees. Data was collected from a sample of 109 respondents, with 22 being women and 87 men. They all worked in managerial positions. The length of work experience ranged from zero months, that is, employees who had no work experience, to those with six and half years of work with the organization. About 22.7 per cent had a degree in management.

The first author collected the primary data by the interview method. The respondents were asked to recall and narrate a critical incident where they had engaged in an act of UI with either a female or a male superior. They were asked to describe briefly the purpose of the influence attempt, what they said or did to influence the superior and how the superior responded to this attempt. They were encouraged to cite examples of or quote what the superior had said.

An examination of the incidents narrated revealed that the issues mentioned were routine, procedural issues and not critical strategic issues. The issues raised were identified as: difference of opinion, work load related to audit, viewpoint related to bank functioning, customer related, getting leave/work timings, and coming up with suggestions.

We divided the transcripts into four categories with the objective of studying gender differences if any, in the UI process.
a. Male agent and female target
b. Male agent and male target
c. Female agent and male target
d. Female agent and female target

Each transcript was assigned a code and all identification details were masked. Coding was done for male and female agents and targets, the strategies employed, and the context in which the interaction was carried out. Based on Kipnis and Schmidt's (1982) classification of UI strategies, we classified the reported UI incidents into the following categories: reason and logic, upward appeal, assertiveness, coalition, ingratiation, exchange, and a category of 'others' that included combination tactics. We studied each transcript to identify the UI strategy used in the instance narrated. At times the respondents used more than one strategy to gain compliance. These were listed separately each time a particular approach was encountered in the reported speech. Strategies that did not find a pure fit in any of the six types were classified under the broad heading of 'others' strategy. 


\section{Scope of study}

We conducted the study in one Indian organization. We expected there to be a degree of similarity in how the respondents addressed the influence situations as organizations have a general prevailing organizational and work culture that governs the general interaction and communication patterns.

The issues discussed for the use of influence were routine organizational issues. Again, a degree of homogeneity was expected to exist in how employees of one organization approach superiors based on the organizational culture.

The sample size taken for the study precludes the generalization of the findings. The findings are indicative rather than representative of the general organizational situation. Cross validation through quantitative analysis will provide more insight into how women and men use FTAs during organizational interactions.

\section{Research questions}

In the following section we shall explore two primary research questions that address our study on gender differences in the use of FTA when reporting acts of UI:

1. What is the impact of threat to face in the choice of UI strategy in different-gender dyads?

a. What is the impact of threat to face on the choice of UI strategy when the agent is male and the target female?

b. What is the impact of threat to face on the choice of UI strategy when the agent is female and the target male?

2. What is the impact of threat to face on the choice of UI strategy in same-gender dyads?

a. What is the impact of threat to face on the choice of UI strategy when the agent and target are both males?

b. What is the impact of threat to face on the choice of UI strategy when the agent and target are both females?

\section{Analysis}

We have selected four transcripts for discussion, which typically represent the strategy found to be most frequently used in each agent-target combination. The transcripts were randomly selected from each of the four combinations. We have selected only parts of the narration of the respondents. The texts have been reproduced without any grammatical or language changes. As English is a second language for the respondents, there were many errors which have been reproduced in the excerpts in the interest of maintaining the authenticity of the text. Additionally as our concern revolved round the verbalization of the influence attempts rather than assessment of the capability in responding in the English language we decided to use the text in its original form.

We made an attempt to identify instances in which FTAs were involved and tried to see if there was a direct correlation between FTAs and choice of UI strategies across the organization.

Research question 1: What is the impact of threat to face on the choice of UI strategy in different-gender dyads?

There has been research (Jaffe et al., 1995; Baker, 1991) on the differences in use of FTAs and politeness between women and men. However a study of the same while applying UI strategies made it an interesting and challenging area of study. 
In the following section, we will:

Present a table listing the strategies and the reported percentage of use of UI strategies.

Produce a sample text drawn from the transcripts reporting use of UI strategies. Explain the context, analyze the text, and explain the UI strategy and FTA used.

A similar treatment has been meted out to the four different combinations of agent and target, that is agent - male, target - male; agent - male, target -female; agent - female, target -male; and, agent - female, target - female. We have picked out the samples as typically indicative of the process of UI in each agent-target combination. In the analysis we have referred to the agent as respondent as the study has been conducted on reported use of UI in critical incidents.

Research question 1a: What is the impact of threat to face on the choice of UI strategy when the agent is male and the target female?

Table 1a

Respondent $-\mathrm{M} \quad$ Target $-\mathrm{F}$

\begin{tabular}{|l|l|}
\hline \multicolumn{1}{|c|}{ Strategies } & $\begin{array}{l}\text { Reported usage (in } \\
\text { percentage) }\end{array}$ \\
\hline Reason and logic & 45 \\
\hline Upward Appeal & 12.15 \\
\hline Assertion & 9 \\
\hline Coalition & 11.79 \\
\hline Ingratiation & 0 \\
\hline Exchange & 0 \\
\hline $\begin{array}{l}\text { Others (use of experience and exposure, fact } \\
\text { revelation, connection, target gratification and } \\
\text { instrumental dependency) }\end{array}$ & 14.06 \\
\hline
\end{tabular}

\section{Context}

The trainee officer (male) approaches his senior officer about a transaction error. According to him the mistake was made by the bank officials and not by the customer, and hence they should rectify the error. The superior (female) was hesitant to do so without adequate documents from the processing department. Through presentation of documents and past transactions the trainee officer was able to convince his superior to the proposed stance.

Respondent: I am handling the salary section also. If the account number does not tally to the customer's name, we are parking their salary into some office account temporarily. After getting confirmation in writing from the office, we will credit to their customer account. Once I know the customer through dayto-day interaction I know this is his account number and the one written by the department is wrong. However, [name] madam said that we should wait for written confirmation from the department. Then I went through the entire history of the customer and showed her that we are crediting the salary into that account number. I took photocopies of the sheets of the salaries on the basis of that I made her agree finally.

Application of UI strategy: The subordinate made use of reason by offering supporting data, to convince the superior to carry forward a certain line of action. He had his facts ready when he went to meet his superior. He expected some amount of opposition as it involved paper work which had to be cleared by another department. On resistance, he produced the necessary documents to show that an error had been made in entering the account number, for which the customer should not be penalized. 
Use of FTA: In this example, the on-record with redressive action approach has been used to gain compliance.

During an interaction for UI, the subordinate has to take care to avoid or minimize threat to the superior's face (Riley, 1993). Here the subordinate approaches the superior and asks her to change the decision to hold back the salary payment. The initial attempt is to have her agree merely by providing convincing talk. When she insists on written documents he produces past records in support of his argument. There is a threat to the positive face of the superior. Insistence to change a decision already taken poses threat to face by pressurizing the superior to comply with something not originally agreed upon. Conviction on the part of the subordinate that they should not be penalizing the customer, even though the superior did not agree, made him apply a more compelling UI strategy. When telling her did not help, he made use of supporting evidence to back his request. The threat was minimized by shifting focus from a personal opposition to compliance based on data.

Research question $\mathbf{l b}$ : What is the impact of threat to face on the choice of UI strategy when the agent is female and the target male?

Table 1b

Respondent $-\mathrm{F} \quad$ Target $-\mathrm{M}$

\begin{tabular}{|l|l|}
\hline \multicolumn{1}{|c|}{ Strategies } & $\begin{array}{c}\text { Reported usage } \\
\text { (in percentage) }\end{array}$ \\
\hline Reason and logic & 44 \\
\hline Upward Appeal & 24 \\
\hline Assertion & 8 \\
\hline Coalition & 8 \\
\hline Ingratiation & 0 \\
\hline Exchange & 0 \\
\hline $\begin{array}{l}\text { Others (use of experience and exposure, fact } \\
\text { revelation, connection, target gratification and } \\
\text { instrumental dependency) }\end{array}$ & 16 \\
\hline
\end{tabular}

\section{Context}

The cash verification officer had to report to the manager, finance department, about the daily transactions. Earlier there was no cut-off time for cheque deposits, which made her wait till late evening to clear all the paperwork before leaving for the day. She talked with the manager about setting up a fixed time schedule so that work could proceed faster.

Respondent: We receive so many cheques. Even a Rs 5/- cheque needs to be entered, you need a printout of that. I used to tell him that there should be a cut-off time to receive cheques that is to be entered the same day. One cannot sit till $8 \mathrm{pm}$ because I have to go to [another city]. So I need to convince him.

Interviewer: So he was convinced. How much time did it take for you to convince him?

Respondent: It took almost a month.

Interviewer: All the time you were trying to convince him. You knew that one day he will be convinced.

Respondent: Because ultimately I am sitting late. After the daily ledgers are completed I have a back-up file to be done .... and I have to sit just for the processing part so that the back-up files are picked up in [the regional center]. 
... when I went on leave for a month [the manager] had to sit and then he realized that this is time wasting and if a cut-off is created it is much easier.

Application of UI strategy: The respondent tried to convince her superior by reasoning that maintaining an all-day ledger entry procedure prolongs their working hours. She is aided in her UI attempt by circumstances which enable her to show her superior the difficulty of her position. She tried to convince him by reasoning that maintaining an all-day ledger entry procedure prolongs their working hours. He was not thoroughly convinced till he experienced the situation himself. The personal experience convinced him of the practicality of what she had been saying.

Use of FTA: A combination of on-record with redressive action and deference politeness is used to mitigate threat to face.

The subordinate has a better alternative to the current practice but does not push her case too strongly. She prefers to leave the final decision to the discretion of the superior. That is why it takes nearly a month for the manager to come around to what she had initially proposed. There too the decision is partly influenced by the manager's personal experience in the subordinate's position.

Research question 2a: What is the impact of threat to face on the choice of UI strategy when the agent and target are both male?

Table 2a

Respondent - M Target - M

\begin{tabular}{|l|l|}
\hline \multicolumn{1}{|c|}{ Strategies } & $\begin{array}{l}\text { Reported usage } \\
\text { (in percentage) }\end{array}$ \\
\hline Reason and logic & 26.02 \\
\hline Upward Appeal & 21.80 \\
\hline Assertion & 9.52 \\
\hline Coalition & 14.14 \\
\hline Ingratiation & 0 \\
\hline Exchange & 0 \\
\hline $\begin{array}{l}\text { Others (use of experience and exposure, fact revelation, } \\
\text { connection, target gratification and instrumental } \\
\text { dependency) }\end{array}$ & 28.52 \\
\hline
\end{tabular}

\section{Context}

The senior manager came to know about an anonymous mail sent against an employee to the regional office. He meets the regional head to clarify that this could be an internal act of personal rivalry and should not be taken seriously enough to initiate action against the employee without adequate verification.

Respondent: Some customer had written a nasty mail about one of our employees - a complaint which was not true. There were some issues involved in it. So he sent mail to our top people in [regional] office and to enquire a committee was set up. This was at the [name of local center]. It was decided to take a harsh action. We had to discuss on it. If anyone comes and says anything, one should produce proof when a customer has written an anonymous e-mail. If customer is true, send mail to the customer and tell him. Otherwise, just like that, any employee might have written. We did a lot of enquiry.

I told [the regional head] to find out the facts before taking action, because first we should know who the customer is, what happened for him to write 
such a letter, etc. or at least, the customer should give his name, telephone number, etc., so that we could contact. The customer has given some reference saying that he knows such and such a person, and it has gone to [regional] office. How does a normal person come to know the e-mail ID - may be an internal person involved in it. I have gone and checked at the [name of another local branch] as he had said that he had some relatives in [last mentioned] branch, and so on. Everyone there denied that they do not know any operations of that kind. I went and told [the regional head] that I have enquired and it seems the claim is a false one, and if action is initiated, it will make someone's life miserable. I suggested that he should call the customer and enquire or drop the case, and tried to impress upon him.

Interviewer: How long did it take for you to convince him?

Respondent: Two or three days, lot of running around.

Interviewer: Then he saw your point of view?

Respondent: After my verifying with the [name of the other local branch] branch, I was confident that no such things could have happened.

Application of UI strategy: The attempt is to influence the regional head to change his decision based on logic. The manager realizes that they may be spoiling an employee's career by taking disciplinary action against him without adequate proof. He offers his argument to the regional head but is not successful. At his position the regional head may not have had the time to look into all the details of the case (Gabarro, 1979). So the manager does some fact finding to verify the truth of the accusations that have been made against the employee. His enquiries show that there is no basis to what the anonymous mail has claimed. The strong evidence in support of his argument casts a doubt on the authenticity of the accusations and the case is dropped.

Use of FTA: The approach used in this example is that of bald on-record.

The threat to face is greater because the subordinate is questioning the judgment of the superior in taking a hasty decision. Earlier literature (Morand and Ocker, 2003) shows that this approach is used mostly when both parties are quite well-known and close to each other and threat to face is minimum. Here, though it is a formal interaction and the power distance is more, the manager's seniority in the organization lends credibility to his opposition.

Research question $2 \boldsymbol{b}$ : What is the impact of threat to face on the choice of UI strategy when the agent and target are both female?

Table 2b

Respondent $-\mathrm{F} \quad$ Target $-\mathrm{F}$

\begin{tabular}{|l|l|}
\hline \multicolumn{1}{|c|}{ Strategies } & $\begin{array}{l}\text { Reported usage } \\
\text { (in percentage) }\end{array}$ \\
\hline Reason and logic & 38 \\
\hline Upward Appeal & 12.5 \\
\hline Assertion & 12 \\
\hline Coalition & 95 \\
\hline Ingratiation & 0 \\
\hline Exchange & 0 \\
\hline $\begin{array}{l}\text { Others (use of experience and exposure, fact } \\
\text { revelation, connection, target gratification and } \\
\text { instrumental dependency) }\end{array}$ & 39 \\
\hline
\end{tabular}




\section{Context}

The junior officer requires her reporting officer's approval for validating customer's claims. In one case the junior thought the papers were not in order so she requested her senior not to pass the application. The latter was hesitant as the customer was a major client. However, through some tactful fact finding the junior officer found her hunch to be correct and the claim was rejected.

Respondent: For validation we need to take the approval [of the senior]. But there is a genuinity as far as the case was concerned [she was concerned about the genuineness of a particular case]. So I told her that we have to check this straightforward with the person and ask whether this could be done. This is like offending a customer or something. Then we worked out how we talk about it to the customer without actually offending him and getting the details. It was difficult to tell her because he is a valued customer. He may withdraw the entire amount. A good amount would be lost. We spoke to the person in a way that he not only put in more money, he gave us exactly the details. We saw some of the discrepancies in the data we had. We did not give him the approval, of course. But what he was claiming was not right. We found out that what he was claiming was wrong.

Application of UI strategy: A combination of strategies - appeal to ethics and collaborating with the superior - was used to convince the reporting officer to reject the claim. There was the use of persuasion through appeal to ethics and legality of procedure. Since the person was a major client of the branch, direct confrontation was not possible even when they doubted the veracity of his claims. The officer had to be told of how the customer will be handled tactfully during the verification of information. Handling the matter capably was also important since the result would have reflected on the caliber of the reporting officer. While there is no use of coalition as a strategy in convincing the superior, the subordinate uses consensus with the superior to get the work done her way (Floyd and Wooldridge, 1992).

Use of FTA: The on-record with redressive action and solidarity politeness principles were employed to convince her that this was not a personal issue and they could work together to get over the problem.

The threat to the positive face of the superior (Knapp, Stafford and Daly, 1986) makes the situation sensitive. She was not ready for directly confronting the customer since had they been proved wrong, and it would have affected the deposits in the bank. The subordinate outlined the approach they can adopt with the customer for verification without turning him off.

\section{Discussion}

Much of the research referred to for this paper indicated some difference in the way women and men use FTAs in conversations and interactions. Guodong and Jing (2005) found women to be more polite and sensitive to status than men. The general trend of research findings has been that women are more polite, use more indirect communication strategies and are compliant as compared with men. However, the degree to which women and men will engage in communication that poses a threat to face cannot be determined merely on the basis of establishing a one-to-one relationship between gender and FTA. Various moderating variables will play a role in determining how much of threat to face an individual will risk in an interaction.

Scant literature was available to us on the interplay of gender and FTA in the organizational context. An empirical study using UI as the purpose of interaction was thought as a first step towards bridging this gap. UI, by its very nature, involves some degree of threat to the positive or negative face of the individuals concerned. Direct or hard strategies like reason and logic, upward appeal and assertion pose greater threat to face than the softer approaches as they openly challenge the decision of the superior. The softer techniques leave scope for the target to choose 
to ignore the influence attempt and also for the agent to avoid through ambiguity an uncomfortable situation.

A look at the transcripts showed that in many of the instances narrated, the respondent was found to have used more than one strategy to gain compliance. However, during the interview the respondent named one or the other strategy as the only one to have been used. This can be attributed to the methodology of data collection, that is, reported speech, which lends itself to secondary interpretation rather than primary observation. Our work finds support in literature that a configurational approach to influence, that is, a combination of strategies is more representative of the pattern of influence actually followed in organizations (Farmer and Maslyn, 1999). Falbe and Yukl (1992) argue that it is actually difficult to identify individual strategies since the subordinate is likely to use a combination of more than one tactics for successful UI.

In the previous section we took samples to illustrate how the FTA is incorporated into an act of UI in the four combinations of dyads. A detailed examination of the study results gives further insight into patterns of use of FTA during UI across gender.

Table 5

\section{Comparison of the use of UI strategies in the four female and male dyads}

\begin{tabular}{|l|r|r|r|r|}
\hline \multicolumn{1}{|c|}{ Strategies } & \multicolumn{1}{|c|}{$\begin{array}{c}\text { M-F } \\
\text { (\% of use) }\end{array}$} & $\begin{array}{c}\text { M-M } \\
\text { (\% of use) }\end{array}$ & $\begin{array}{c}\text { F-M } \\
\text { (\% of use) }\end{array}$ & $\begin{array}{c}\text { F-F } \\
\text { (\% of use) }\end{array}$ \\
\hline Reason and logic & 45 & 26.02 & 44 & 38 \\
\hline Upward Appeal & 12.15 & 21.80 & 24 & 12.5 \\
\hline Assertion & 9 & 9.52 & 8 & 12 \\
\hline Coalition & 11.79 & 14.14 & 8 & 95 \\
\hline Ingratiation & 0 & 0 & 0 & 0 \\
\hline Exchange (use of experience and & 14.06 & 28.52 & 16 & 39 \\
\hline $\begin{array}{l}\text { Others (use } \\
\text { exposure, fact revelation, connection, } \\
\text { target gratification and instrumental } \\
\text { dependency) }\end{array}$ & & & 0 & \\
\hline
\end{tabular}

When the agent and the target were of opposite genders, reason and logic was the strategy most likely to be used to gain compliance. While much of the earlier research shows women to use softer strategies of UI, here they used direct and hard tactics as much as men, if not more, to influence the superior. Reasoning was considered objective and result oriented. Statements such as, "I used to convince him that as there are lot of ladies already there...", "...if I am there for the presentation, the result would be better", "... a lady approaching a lady would have more effective and comfortable", "I also used to give him statistical data and make him agree for my being there for the presentation", illustrate the use of realistic and practical arguments to influence the superior. Reason and logic is generally used when the threat to face is lower (Waldera, 1988) and the agent can use the bald-on-record approach (Morand and Ocker, 2003; "Examples from Brown", n.d.; Ferencik, n.d.) for gaining compliance. The threat is to the negative face of the target, since the issue has more to do with the situation rather than any personal characteristic of the interactants.

Upward appeal came across as an accepted practice amongst many of the respondents. As one of them explained, the work culture encourages them to be open with their superiors. This reduces the strict adherence to hierarchical formalities and makes the working environment more open. Possibly, the open organizational culture encouraged employees to approach higher-ups with issues if it did not get resolved at the department level. From the perspective of use of FTAs, this strategy poses threat to the positive and negative face of the target. In several instances, even when the respondent did engage in upward appeal, it was done with the knowledge of the immediate superior or by keeping the latter in the information loop. At times the subordinate and 
superior approached the next higher-up together in order to sort out the difficulty (Maslyn, Farmer and Fedor, 1996).

When the agent and the target were both male then a combination of strategies was used marginally more than reason and logic to gain compliance. Men found it easier to convince their male superiors when several approaches were combined for better effect. Upward appeal was considered an accepted form of gaining compliance.

Coalition found heavy usage in the F-F combination. This will find support in literature which propounds that women favor softer, cooperative methods of work (Jaffe et al., 1995; DuBrin, 1991) as compared with aggressive and competitive ones. Thus, they are more likely to use solidarity politeness during acts of UI.

Interestingly, none of the four agent-target combinations (M-F, M-M, F-M, and F-F) reported the use of ingratiation and exchange for UI. The Indian socio-cultural norms attached to doing work for a senior, whether by age or rank, may explain why ingratiation is not considered as a strategy to be used consciously for influencing. Subordinates may undertake personal assignments on behalf of the superior, not because it may accrue some benefits in the future, but because it is part of the cultural ethos. If we were to apply the same socio-cultural pattern to exchange, in the traditional Indian hierarchical structure the superior or senior is the one who 'gives' and the subordinate 'receives'. Exchange breaks this pattern by assuming a relationship based on equal give and take from both sides.

Assertion was the least used by any of the combinations. Unless we study this strategy as a communication tactic to gain compliance, it is difficult to identify it in the scripts under study. An understanding of the term as taking a stand and then pursuing it with reason and logic was definitely found in all the scripts. However it was never in isolation but always in combination with reason and logic, which happens to be the most frequently used strategy in the data we have.

In contrast with earlier literature that found that men use more hard or direct tactics (Baxter, 1984; Johnson, 1976), assertion was the least frequently used of all the strategies, whether the target was a woman or a man. Again, in contrast with some research findings that women use indirect strategies for gaining compliance (DuBrin, 1991), a majority of the women respondents in this study applied logic and reasoning, a direct strategy, for UI.

Content analysis of the UI situations narrated during the interviews gave an indication of the likelihood of an FTA being employed in any of the four agent-target combinations.

The results may be extrapolated as follows:

Table 6: Extrapolations from study

\begin{tabular}{|l|c|c|c|c|}
\hline \multicolumn{1}{|c|}{ Strategies } & M-F & M-M & F-M & F-F \\
\hline Bald on-record & $\checkmark$ & $\checkmark$ & $\checkmark$ & \\
\hline On-record with redressive action & & $\checkmark$ & & $\checkmark$ \\
\hline Solidarity politeness & & & & $\checkmark$ \\
\hline Deference politeness & & & $\checkmark$ & \\
\hline Off-record & \multicolumn{3}{|r|}{$\begin{array}{r}\text { The threat to face is too high for the agent to } \\
\text { engage in UI }\end{array}$} \\
\hline Say nothing at all & \multicolumn{4}{|r|}{} \\
\hline
\end{tabular}

Bald-on-record found wide usage among the first dyads. This finds support in the findings discussed earlier where reason and logic were considered the most widely used UI strategy. Application of this strategy is in conformity with Grice's Maxims of quantity, quality, relation and manner (Grice, 1975), which are to be followed for maximum effectiveness in conversation. 
(We have used the word conversation synonymously with communication as most of the principles governing conversation are the same as communication). Same-gender dyads employed on-record FTA with redressive action gaining compliance. As the hierarchies are very strong in India, on-record FTA with redressive action was employed. Interestingly this strategy was used only in the same gender dyads. We can state that as the bonding in the same gender dyad was higher than in the mixed gender dyad, the agent attempted to use positive politeness by mitigating the threat to face of the target by resorting to redressive action. As Baxter (1984) argues that there would be "greater politeness" in relationships involving close friends. Additionally it was found that in the same gender dyads a combination of UI strategies were used, rather than a single strategy. When one approach did not work the agent adopted another till the desired response was elicited. The F-F dyad favored the use of solidarity politeness for successful UI. Our study gave limited evidence of deference politeness being used in any of the dyads. Examples of such patterns are dependent on the social factors in the use of language which are reflected in the use of honorifics (Brown and Levinson, 1987). Only the F-M dyad provided some scope for this approach to be used. As these patterns are not found in the social context of the organization, there is limited use of deference politeness. Similarly, off-record was found to have been pursued only in the M-M dyad. Respondents in this category mentioned meeting their superiors outside the workplace in social or organizational gatherings where they dropped a hint of what they wanted to be done. As "outside organization" meetings and partying are more common for men in the Indian context, the UI is attempted indirectly "so that the meaning is to some degree negotiable" (Brown and Levinson, 1987).

In our study, women respondents did not narrate any instance where they tried to influence their superior outside a formal interaction. Application of FTAs in such situations therefore did not arise. The same was the case in instances when the agent was a male and target (superior) female.

\section{Conclusion}

Our study throws up interesting dimensions to the study of interactional patterns across gender. Some earlier studies (van Vianen and Fischer, 2002; Johnson, Funk and Warner, 1995) found inherent differences between women and men in their patterns of interaction. Our aim was to explore if this difference translates into a difference between the two in the use of FTAs. The results of our study indicate that FTAs are not gender specific in acts of UI. They are more contextual and governed by the organizational culture and the social context of the participants. One of the reasons that can be attributed for this result is the nature of tasks reported while recalling incidents of UI. As stated earlier, the tasks described related to routine work. In routine tasks the threat to face is low as the interplay between individual and interpersonal dynamics which determine and establish a pattern for and of organizational interaction.

In the organizational context, there is more of an 'organizationally fit' pattern of communication that is used. Brown and Levinson's (1987) concept of relative power and social distance between agent and target determine the choice and application of FTAs. This is based on the organizational and work culture and established patterns of communication across hierarchies. It will be false to state that merely the gender of the agent or the target impacts the choice of words used to save "face".

\section{Direction for future research}

As gender diversity in the workplace gains importance, the emphasis on interactional pattern of women and men in the workplace becomes more relevant. To the best of our knowledge hardly any work has been done to study the interplay of gender and FTA in the context of UI. This creates the space to conduct further studies in the field and gain a macro perspective to the subject. 
The use of reported speech for interactional analysis is a new approach which does not find much mention in the literature that we accessed for this paper. While there are limitations to the narrative method, such as accuracy of recall and degree of subjectivity, employing this technique for data collection will enable researchers to examine organizational situations where direct observation is not possible. Combining this technique with other approaches will also help in cross-validating data and exploring other dimensions to the subject.

Expanding the study to several organizations across industry sectors will bring out the role of diversity and organizational culture in the use of FTAs by women and men in their choice of UI strategy. 


\section{References}

Adams, Carey H. and Shepherd, Gregory J. (1996). Managing volunteer performance: Face support and situational features as predictors of volunteers' evaluations of regulative messages. Management Communication Quarterly, 9(4), 363-388.

Baker, Margaret Ann (1991). Gender and verbal communication in professional settings. Management Communication, 5(1), 36-63.

Baxter, L. A. (1984). An investigation of compliance-gaining as politeness. Human Communication Research, 10(3), 424-456.

Brown, Penelope, and Levinson, Stephen C. (1987). Politeness: Some Universals in Language Usage. Cambridge, UK: Cambridge University Press.

Carli, Linda L. (1989). Gender differences in interaction style and influence. Journal of Personality and Social Psychology, 56(4), 565-576.

Deluga, Ronald J. and Perry, J. T. (1991). The relationship of subordinate upward influencing behaviour, satisfaction and perceived superior effectiveness with leader-member exchanges. Journal of Occupational Psychology, 64(3), 239-252.

DuBrin, Andrew J. (1991). Sex and gender differences in tactics of influence. Psychological Reports, 68(2), 635-646.

Eagly, A. H. and Johnson, B. T. (1990). Gender and leadership style: A meta-analysis. Psychological Bulletin, 108(2), 233-256.

Falbe, Cecilia, M., and Yukl, Gary (1992). Consequences for managers of using single influence tactics and combinations of tactics. Academy of Management Journal, 35(3), 638-652.

Falbo, Toni and Peplau, Letitia Anne (1980). Power strategies in intimate relationships. Journal of Personality and Social Psychology, 38(4), 618-628.

Farmer, Steven M. and Maslyn, John M. (1999). Why are styles of upward influence neglected? Making the case for a configurational approach to influences. Journal of Management, 25(5), 653-682.

Floyd, Steven W. and Wooldridge, Bill (1992). Managing strategic consensus: The foundation of effective implementation. Academy of Management Executive, 6(4), 27-39.

Gabarro, John (1979). Socialization at the top: How CEOs and subordinates evolve interpersonal contracts. Organizational Dynamics, 7(3), 3-23.

Gardner III, William L. (1992). Lessons in organizational dramaturgy: The art of impression management. Organizational Dynamics, 21(1), 33-46.

Gersick, Connie J. G., Bartunek, Jean M., and Dutton, Jane E. (2000). The importance of relationships in professional life. Academy of Management Journal, 43(6), 1026-1044.

Grice, H.P. (1975). Logic and conversation. In Cole and Morgan eds. Syntax and Semantics. New York: Academic Press, 1975, pp.41-58.

Guodong, Liang, and Jing, Han (2005). A contrastive study on disagreement strategies for politeness between American English and Mandarin English. Asian EFL Journal, 7(1). Retrieved on 13 February 2006 from http://www.asian-efl-journal.com/march_05_lghj.php.

Johnson, Danefle Ifert, Roloff, Michael E., and Riffee, Melissa A. (2004). Politeness theory and refusals of requests: Face threat as a function of expressed obstacles. Communication Studies, $55(2), 227-238$. 
Johnson, Cathryn, Funk, S., and Clay-Warner, J. (1995). Organizational contexts and conversation patterns in same-sex task groups. Paper presented at the annual meeting of the American Psychological Association, Washington D.C.

Johnson, Paula (1976). Women and Power: Toward a theory of effectiveness. Journal of Social Issues, 32(3), 99-110.

Kaul, Asha, and Brammer, Charlotte D. (2004). Study of Speech Act Theory in upward influencing in an Indian workplace. Proceedings of the 2004 Association for Business Communication Annual Convention.

Kipnis, David and Schmidt, Stuart M. (1988). Upward-influence style: Relationship with performance evaluations, salary, and stress. Administrative Science Quarterly, 33(4), 528-542.

Kipnis, David, and Schmidt, Stuart M. (1982). Profiles of organizational influence strategies (Form M). San Diego, CA: University Associates.

Kipnis, David, Schmidt, Stuart M., and Wilkinson, Ian (1980). Intraorganizational influence tactics: Explorations in getting one's way. Journal of Applied Psychology, 65(4), 440-452.

Kipnis, David, and Vanderveer, Richard (1971). Ingratiation and the use of power. Journal of Personality and Social Psychology, 17(3), 280-286.

Knapp, Mark L. Stafford, Laura, and Daly, John A. (1986). Regrettable messages: Things people wish they hadn't said. Journal of Communication, 36(4), 40-58.

Lamude, Kevin G. (1993). Survivors' upward influence tactics in same-sex and cross-sex dyads. Perceptual and Motor Skills, 77(3), 1067-1070

Lauterbach, K. E., and Weiner, B. J. (1996). Dynamics of upward influence: How male and female managers get their way. Leadership Quarterly, 7(1), 87-107.

Liden, Robert C. and Mitchell, Terence R. (1988). Ingratiatory behaviors in organizational settings. Academy of Management Review, 13(4), 572-587.

Mainiero, Lisa A. (1986). Coping with powerlessness: The relationship of gender and job dependency to empowerment-strategy usage. Administrative Science Quarterly, 31(4), 633-653.

Maslyn, John M., Farmer, Steven, M., and Fedor, Donald, B. (1996). Failed upward influence attempts: Predicting the nature of subordinate persistence in pursuit of organization management. Group and Organization Management, 21(4), 461-480.

Mechanic, David. (1962). Sources of power of lower participants in complex organizations. Administrative Science Quarterly, 7(3), 349-364.

Morand, David A. and Ocker, Rosalie J. (2003). Politeness theory and computer-mediated communication: A sociolinguistic approach to analyzing relational messages. Proceedings of the $36^{\text {th }}$ Hawaii International Conference on System Sciences (HICS). IEEE.

O'Neil, Julie (2004). Effects of gender and power on PR managers' upward influence. Journal of Managerial Issues, 16(1), 127-144.

Riley, Kathryn (1993). Telling more than the truth: Implicature, speech acts, and ethics in professional communication. Journal of Business Ethics, 12(3), 179-196.

Sagrestano, Lynda (1992). Power strategies in interpersonal relationships. Psychology of Women Quarterly, 16(4), 481-495.

Schilit, Warren K. and Locke, Edwin A. (1982). A study of upward influence in organizations. Administrative Science Quarterly, 27(2), 304-316. 
Thacker, Rebecca A. and Wayne, Sandy J. (1995). An examination of the relationship between upward influence tactics and assessments of promotability. Journal of Management, 21(4), 739756.

van Vianen, Annelies E. M. and Fischer, Agneta H. (2002). Illuminating the glass ceiling: The role of organizational culture preferences. Journal of Occupational and Organizational Psychology, 75(3), 315-337.

Waldera, L. M. (1988). A study of key variables related to the directness of upward influence strategies and to self perceptions of upward influence. Dissertation Abstracts International, 50, 02B.

Waldron, V. R., Hunt, M. D., and D'Silva, M. (1993). Toward a threat management model of upward communication: A study of influence and maintenance tactics in the leader-member dyad. Communication Studies, 44, 254-272.

White, Judith B., Tynan, Renee, Galinsky, Adam D., and Thompson, Leigh (2004). Face threat sensitivity in negotiation: Roadblock to agreement and joint gain. Organizational Behavior and Human Decision Processes, 94, 102-124.

Wilkins, Brenda M. and Andersen, Peter A. (1991). Gender differences and similarities in management communication: A meta-analysis. Management Communication Quarterly, 5(1), 635 .

Yukl, G. and Tracey, J. B. (1992). Consequences of influence tactics used with subordinates, peers and the boss. Journal of Applied Psychology, 77, 525-535.

Yukl, G. (1998). Leadership in Organizations, fourth edition. Upper Saddle River, NJ: PrenticeHall.

\section{Web links}

Examples from Brown and Levinson's politeness strategies (n.d.). Retrieved on 13 February 2006 from http://logos.uoregon.edu/explore/socioling/strat.html.

Ferencik, Milan (n.d.). Pragmalinguistics and stylistics. A Survey of English Stylistics. Retrieved on 13 February 2006 from http://www.pulib.sk/elpub/FF/Ferencik/10.pdf.

Gardner-Chloros, Penelope, and Finnis, Katerina, (n. d.). Code-switching, gender and politeness: A study in the London Greek-Cypriot community. Retrieved on 5 December 2005 from http://webs.uvigo.es/ssl/actas2002/07/06.\%20Penelope\%20Gardner.pdf.

Jaffe, J. Michael, Lee, Young-Eum, Huang, Lining, and Oshagan, Hayg (1995). Gender, pseudonyms, and CMC: Masking identities and baring souls. Paper submitted for presentation to the 45th Annual Conference of the International Communication Association, 1995, Albuquerque,

New Mexico, USA. Retrieved on 13 February 2006 from http://members.iworld.net/yesunny/genderps.html.

Mills, Sara (2002). Rethinking politeness, impoliteness, and gender identity. Gender identity and discourse analysis, 69-89. Retrieved on 5 December 2005 from http://www.linguisticpoliteness.eclipse.co.uk/Gender\%20and\%20Politeness.htm.

White, Ron (1997). Minding your maxims. Retrieved on 13 February 2006 from http://www.rdg.ac.uk/app_ling/maxims.htm\#E\%20text. 